Article

\title{
A Spoonful of Sugar: Gamification as Means for Enhancing Employee Self-Leadership and Self-Concordance at Work
}

\author{
Richard A. Oxarart* and Jeffery D. Houghton (D) \\ Department of Management, West Virginia University, Morgantown, WV 26506, USA; \\ jeff.houghton@mail.wvu.edu \\ * Correspondence: rao0009@mix.wvu.edu
}

Citation: Oxarart, Richard A., and Jeffery D. Houghton. 2021. A Spoonful of Sugar: Gamification as Means for Enhancing Employee Self-Leadership and Self-

Concordance at Work. Administrative Sciences 11: 35. https://doi.org/ 10.3390/admsci11020035

Received: 2 March 2021

Accepted: 29 March 2021

Published: 6 April 2021

Publisher's Note: MDPI stays neutral with regard to jurisdictional claims in published maps and institutional affiliations.

Copyright: (c) 2021 by the authors. Licensee MDPI, Basel, Switzerland. This article is an open access article distributed under the terms and conditions of the Creative Commons Attribution (CC BY) license (https:// creativecommons.org/licenses/by/ $4.0 /)$.

\begin{abstract}
Organizations today continue to seek new and effective ways to engage and motivate their workers. Gamification is an emerging means for enhancing employee engagement and motivation at work. Self-leadership is a comprehensive self-influence process that has the potential to help employees find meaning and purpose from their jobs. This paper develops and presents a conceptual model of the relationships between gamification, self-leadership, and valued workplace outcomes. The model suggests that gamification elements trigger multiple self-leadership processes and states that interact in a multiplicative fashion leading to a state of self-concordance in which individuals perceive a close alignment between their work tasks and their personal interests and core values. This serial mediation model helps to explain how and why gamification operates through the mediating mechanisms of self-leadership and self-concordance to effect important individual and organizational outcomes. Future research directions and implications for the proposed conceptual model are also discussed.
\end{abstract}

Keywords: gamification; self-leadership; self-determination; self-concordance; self-efficacy; creativity

"In every job that must be done, there is an element of fun.

You find the fun and snap! The job's a game!"

-From the song A Spoonful of Sugar Helps the Medicine Go Down in the movie Mary Poppins

\section{Introduction}

Organizational leaders have long sought after the most effective ways to engage and motivate their workforce. These efforts become even more challenging as the workforce itself changes and evolves over time. Recently, Larry Clark, the managing director of global learning solutions at Harvard Business Publishing Corporate Learning, suggested that the global workforce is experiencing three key shifts that may help organizations understand how they need to think and act differently in order to engage and motivate their employees (Clark 2020). He argues that generational diversity, continuous learning, and the search for meaning at work will define what he calls the workforce of the future (Clark 2020). He further suggests that this new workforce is asking for three things in order to be engaged: include me (allow me to bring my own values and diversity into the workplace), inspire me (with a combination of autonomy and purpose), and grow me (with career pathways and learning opportunities) (Clark 2020).

Gamification, which involves applying elements from game design in non-game contexts, (e.g., Deterding et al. 2011), is one potential means through which organizations may be able to effectively engage and motivate a new generation of workers. Game elements, when added to jobs, marketing campaigns, social media platforms, and other contexts, have been found to produce a variety of positive outcomes (Sailer et al. 2017; Landers et al. 2018). Furthermore, the list of companies that are making use of gamification elements within their organizations continues to grow (e.g., Cisco, Aetna, Nike, Google, 
Deloitte, Samsung, and Siemens). Still, relatively little work has been done within the literature on gamification regarding how these game elements are able to motivate these valuable outcomes. Indeed, the theoretical mechanisms that underlie the motivational properties of gamification have been largely neglected and are oftentimes dismissed with vague nods to established theories in the social sciences (e.g., self-determination theory, social cognitive theory, etc.).

In this paper, we seek to provide some clarity to this issue by examining self-leadership, a comprehensive process of self-influence through which people can shape their own cognitive and behavioral outcomes (e.g., Stewart et al. 2011, 2019), as a possible explanation for how gamification can increase valuable outcomes in the work environment. We develop and present a theory-based conceptual model of gamification and self-leadership along with a series of supporting research propositions. In short, our model suggests that gamification elements will trigger interactive self-leadership processes that will result in a state of self-concordance, which occurs when work tasks closely align with an individual's interests and core values (Sheldon and Elliot 1999), and ultimately with key outcomes. Therefore, the aim of this current research is to better understand the role of self-leadership in the context of a gamified working environment and how these can lead to employee feelings of self-concordance. As many companies have begun using gamification design principles, we suggest that it is incumbent on the research community to study its effects on employees and organizations. Our current research offers a conceptual model that can guide future researchers in meeting that goal.

Our paper and conceptual model offer a number of contributions to the gamification and self-leadership literatures. First, our model aims to provide some additional theoretical underpinnings to explain the mechanisms and processes through which gamification can affect valued outcomes. Second, much of the self-leadership literature has positioned self-leadership as a key antecedent to various outcomes (Stewart et al. 2011, 2019). Studies exploring the antecedents of self-leadership are rare (for a notable exception see Cristofaro and Giardino 2020). Consequently, we add to the self-leadership literature by exploring gamification as a possible antecedent of self-leadership, and self-leadership processes as a possible mediating mechanism through which gamification influences outcomes. Stated differently, we examine gamification as a potentially useful job design system that could increase individual self-leadership.

\section{Gamification}

To understand the proposed relationship between self-leadership and gamification, we must first define and investigate what gamification is, how it has been studied, and why it could be potentially useful in the context of management. Gamification has been defined in the literature as the "use of game design elements within non-game contexts" (Deterding et al. 2011, p. 9). Though this definition is broad, it differentiates the construct from other related concepts, such as serious games. Serious games aim to increase learning with actual games, while gamification, in contrast, uses gamification elements that have various motivational properties within a non-game context. For instance, a commonly used and easily understood gamification element is the use of points and levels. Points and levels can be injected into almost any existing system wherein user actions can be quantified. Therefore, gamification is not the creation of games in an effort to motivate people, but rather is the incorporation of game elements into otherwise normal or mundane systems. Nevertheless, the use of such game elements do make these normal systems and activities appear more game-like in nature.

Gamification has been used in a wide variety of contexts, including training and development (Armstrong and Landers 2018; Baxter et al. 2016; Tansley et al. 2016), performance management systems (Armstrong et al. 2016; Cardador et al. 2017), marketing (Robson et al. 2014), energy conservation campaigns (Wee and Choong 2019), and education (Buckley et al. 2017; Hanus and Fox 2015). Indeed, many of the common apps used in our modern world demonstrate the prevalence of gamification elements. For instance, the 
recent popularity of Noom, a behaviorally focused weight loss app, displays the efficacy of using gamification elements within an otherwise non-game context. Audible, a popular audiobook platform, makes use of badges and other gamification elements to motivate and encourage the use of their app. Applications of gamification elements within our modern world are myriad and so ubiquitous that they almost go unnoticed or unexamined. Still, research on this potentially useful construct and tool has received increased research attention over the past decade in an effort to understand its effects on human behavior and cognition (Cardador et al. 2017; Feng et al. 2018; Sailer et al. 2017; Sailer and Homner 2020).

\subsection{Gamification Elements}

Many game elements could be used in the gamification of otherwise mundane activities, but some have been described and studied more fully in the growing gamification literature (Landers et al. 2017; Sailer et al. 2017; Sailer and Homner 2020; Bedwell et al. 2012; Dicheva et al. 2015; Wilson et al. 2009). In this section, we briefly describe some of these gamification elements. Importantly, gamification elements have mostly been studied as bundles, rather than in isolation.

Gamification most often involves a system of points and levels. Points are a quantified form of feedback to users and are found in both gamified and non-game contexts. Points go by various names and sometimes have their labels modified to fit the context in which they are being used (e.g., "experience points"). Furthermore, points are generally coupled with levels, which are essentially cutoffs at which new benefits and/or responsibilities are gained. Oftentimes, when a certain amount of points is attained by a user, levels are awarded. Levels can convey a kind of status that may stretch beyond the limits of the gamified system itself. For instance, frequent flyer miles could be considered a type of points, while earning a silver, gold, or platinum status within a given program would be considered a type of level that conveys a sense of social status.

Leaderboards are also commonly used in gamified systems to tap into a more competitive or relational urge for comparing one's progress and achievements to others. Leaderboards usually involve a ranking system that shows who is performing best in the gamified system. These rankings can be based on progress, levels, points, or general performance. Furthermore, these ranking systems are usually visible to the participants, so that they can see how well they are doing relative to others. Empirical research has shown that leaderboards can successfully increase employee task performance (Landers et al. 2015). Furthermore, in one recent report, Amazon has been making use of gamification in their warehouses to increase productivity of their employees (Statt 2021). These systems allow employees to enter their shift results into a leaderboard where they can be ranked among other workers in that warehouse and other Amazon warehouses. Amazon must think these systems are beneficial, as they are reportedly adding more of these gamified systems in at least twenty additional fulfilment centers (Statt 2021).

Badge systems are also a common type of gamification element found in these types of systems. They are usually award for activities, performance, or behaviors that are considered extra-role or outside the normal required scope of the tasks or job (Sailer et al. 2017; Hamari 2017). For instance, in a college course, a student might earn a badge for having read an academic article that was not assigned as a normal part of the course, but was instead a "recommended reading" that could be useful in reinforcing the learning objectives for the course. Badges systems are also used in consumer products in an attempt to increase engagement. For instance, Audible.com uses badge systems in their app, awarding badges for activities such as rereading a book multiple times.

Collaboration/competition is another common element in most games and gamified systems and refers to the competitive or cooperative nature of games and game systems. Sometimes collaboration and competition work in concert with one another. For example, sport teams must cooperate to compete against other teams (i.e., football, basketball, etc.). This is also true of virtual games in which teammates and/or competitors are non-player characters (NPCs) controlled by various game mechanics or artificial intelligence (AI). 
Avatars are a visual representation of a participant within a game or gamified context. Avatars can be as simple as the top hat token, in the case of Monopoly, or as complex as a three-dimensional representation of the participant in a virtual setting (Sailer et al. 2017). These avatars can take on incredible meaning for participants in some online environments as a forward-facing representation of themselves. For instance, in a popular online game for children called Roblox, players spend a great deal of time and money to customize their avatar and buy outfits or modifications for their avatars. This may seem silly in many respects to an outsider looking in, but for these participants it is akin to wearing the latest fashions or engaging in personal grooming before going out. For some people, their avatar's appearance and movements are very important, representing their actual or ideal self in the game context.

Narratives and themes are another common element within gamification. Stories and themes built around a gamified system can add gravity or levity to what would otherwise be a mundane activity. A well-crafted story overlaid onto tasks or jobs can increase engagement and "alter the meaning of real world activities" (Sailer et al. 2017, p. 373). These narratives and themes vary widely in both complexity and substance. For instance, a theme could be simply a horse trying to win a race, or a whole world with intriguing backgrounds and histories where participants must interact with and change the world in some fantastic way. In either case, interesting contexts are added to mundane tasks, projects, and jobs, enhancing them with imagined meaning to increase overall interest and engagement.

One final gamification element we will discuss here is that of choices. Choices are seldom studied as a common gamification element (Charsky 2010), but they are clearly a crucial part of games and game environments. As Rollings and Morris (2000, p. 38) observed, "a game is a series of interesting choices." In fact, the efficacy of many other gamification elements hinge on this important game element. For instance, points essentially provide feedback on choices (better choices lead to more points). Similarly, the creation and selection of avatars are based on a series of choices by the user. Therefore, we suggest that choices are a critical element that should be discussed in any gamification research.

\subsection{Gamification Outcomes and Research}

Gamification has been studied in a variety of contexts and has been found to positively affect various outcomes of interest for organizations. For instance, in empirical studies, gamification has been found to increase user activity (Hamari 2017), motivation (Kyewski and Krämer 2018), affective reaction to training (Sailer et al. 2017), engagement (Aldemir et al. 2018; Barata et al. 2017; Santhanam et al. 2016), task performance (Landers and Armstrong 2017; Mekler et al. 2017), and perceived task meaningfulness (Sailer et al. 2017). Furthermore, gamification has been examined for use in educational settings (Buckley et al. 2017; Domínguez et al. 2013), consumer marketing experiences (Robson et al. 2014; Hamari 2017), and organizational settings (Armstrong and Landers 2018; Landers et al. 2017; Baxter et al. 2016; Silic and Lowry 2020). Still, some mixed results have been found for the effectiveness and use of gamification in these contexts. For instance, Kyewski and Krämer (2018) found that for a sample of students, badges did not have a very strong effect on motivation, user activity, or student performance. Furthermore, they found that when badges were public and viewable by other students in the class, they were viewed less positively than if they were hidden from all but the student who earned them (Kyewski and Krämer 2018). Additionally, Mekler et al. (2017) performed an experiment and found that gamification only increased the quantity of tasks completed, but did not improve the quality of the work. These findings may have important implications regarding usefulness of gamification.

Other problems exist within the study of gamification. For instance, some gamification elements suffer from definitional problems and issues with the operationalization of these constructs. For example, Kyewski and Krämer (2018) gave badges for classwork that was required as part of a college course, which runs counter to the conceptual definition of 
badges described above, namely that badges should be awarded for extra-role behaviors and not for required tasks. Furthermore, these badges were studied in isolation from other gamification elements and, as noted above, gamification is usually studied in terms of bundles of game elements (Mekler et al. 2017; Nacke and Deterding 2017; Sailer et al. 2017). The importance of exploring bundles of gamification elements will become clearer as we develop the relationships in our proposed conceptual model.

\section{Self-Leadership}

Self-leadership is a comprehensive self-influence process involving both behavioral and cognitive states and strategies aimed at positively shaping individual performance outcomes (Neck et al. 2020; Stewart et al. 2011, 2019). Inspired by Kerr and Jermier (1978) conceptualization of "substitutes for leadership," Manz and Sims (1980) suggested that one such substitute could be followers' abilities to engage in self-management. They went on to explain that individuals can manage their own behaviors by setting their own performance standards, evaluating their own performance relative to those standards, and administering positive and negative consequences for themselves relative to their evaluations (Manz and Sims 1980). Specific self-management procedures include self-observation (i.e., gathering data about one's behavior that serves as a baseline for subsequent evaluation and consequences), self-goal-setting (i.e., specifying goals for oneself), and self-rewards (i.e., establishing self-evaluation-based reward contingencies) (Manz and Sims 1980). Behavioral self-management subsequently became established as an effective means for shaping behaviors and performance outcomes in the workplace (e.g., Andrasik and Heimberg 1982; Frayne and Latham 1987; Frayne and Latham 1988; Saks and Ashforth 1996).

Manz $(1986,1991)$ later argued that behavioral self-management painted an incomplete picture of the full scope and potential of employee self-influence at work. He introduced the concept of self-leadership as an expanded and more comprehensive process involving a higher level of self-influence and a wider range of self-influence states and strategies (Manz 1986). Manz (1991) described the differences between self-leadership and self-management with three basic questions: "What?" "Why?" and "How?" He noted that self-management's self-influence processes and strategies focus primarily on how tasks are to be accomplished in order to meet externally set standards and objectives while relying largely on extrinsic motivation and focusing primarily on behavior (Manz 1991). In contrast, self-leadership's self-influence processes and strategies address what should be done (i.e., developing the standards and objectives) and why it should be done (i.e., engaging in strategic analysis) in addition to simply determining how the task should be done (Manz 1991). Moreover, self-leadership fosters intrinsically motivating states and involves a much greater focus on cognitive processes (Manz 1986, 1991).

In conceptualizing self-leadership, Manz (1986) noted that self-management involves rewards, such as self-praise or external recognition, that are separate from the task itself. Drawing on self-determination theory (Deci and Ryan 1983) as a conceptual foundation, he described the broader self-leadership perspective as explicitly emphasizing rewards resulting from the tasks themselves, which he called "natural rewards" (Manz 1986, p. 591). He went on to detail three naturally rewarding states that he suggested would be associated with self-leadership's higher level of self-influence: feelings of competence, feelings of selfdetermination or self-control, and feelings of purpose (Manz 1986). Feelings of competence stem from viewing oneself as effective and capable relative to a specific task or activity (White 1959). For instance, someone who is an adept skier is likely to experience feelings of competence from the activity of skiing itself that will motivate them to continue to ski and refine their skills, apart from any external rewards or compliments from other. Feelings of self-control result when individuals see their behaviors as self-chosen and self-directed, rather than dictated, pressured, or coerced by someone else (DeCharms 1968). Activities in which people are free to choose their actions and performance methods tend to enhance their feelings of self-control. For example, the skier who is free to choose which slopes to ski, how fast to ski, and with what techniques will likely be more motivated by the 
activity of skiing than a member of the ski patrol, whose actions on the slopes are largely determined by rules, regulations, and the external expectations associated with their jobs. Finally, feelings of purpose flow from a sense that one's participation in a task or activity is meaningful, worthwhile, and self-relevant (cf. Vansteenkiste et al. 2018). Even if an activity makes a person feel more competent and more self-controlled, motivation may still be lacking if the person finds the task to be meaningless and irrelevant. As an example, altruism, the selfless concern for the well-being of others, is one way in which activities may be imbued with purpose (Smith 2018). Hence, the ski patrol members may still find their work to be naturally rewarding if they find meaning and purpose in helping others on the slopes.

Certain specific natural reward strategies may complement self-management strategies of self-observation, self-goal-setting, and self-reward (Andrasik and Heimberg 1982; Manz and Sims 1980) in order to enhance feelings of competence, self-control, and purpose (Manz 1986; Neck et al. 2020). First, work context strategies involve choosing or structuring one's work environment so that it is more naturally rewarding (Manz 1986). For instance, decorating one's work space with objects and photographs the reflect one's values, interests, and past accomplishments, or choosing to run on a beautiful mountain trail rather than on a quarter-mile track can enhance feelings of self-control (choosing one's environment), feelings of competence (highlighting one's current and past accomplishments), and feelings of purpose (connecting to one's values and adding meaningfulness). Second, task performance process strategies focus on how a given task is performed and involve building naturally rewarding activities into the task wherever possible (Manz 1986). Listening to music or a podcast while performing an otherwise uninteresting task is likely to make the activity more enjoyable and more naturally motivating. Third, task focus strategies involve shifting the focus of one's thoughts to the more pleasant and naturally rewarding aspects of a task (Neck et al. 2020). Most activities include both pleasant and unpleasant aspects, and this strategy involves choosing to think about the parts of a task that one enjoys, rather than the parts that one dislikes. For instance, first-year doctoral students required to read a large number of journal articles could focus on the fact that they did not choose the articles, on the large number of pages assigned, on their inability to understand the complex research methods used in the studies, and on their perceived disconnect between the narrow and esoteric academic research topics and their past work experiences. Such a focus would doubtless undermine intrinsic motivation by reducing feelings of self-control (the articles were arbitrarily assigned), feelings of competence (lack of knowledge of research methods), and feelings of purpose (esoteric research topics disconnected from practice). In contrast, these students could choose to focus their thoughts on the naturally rewarding aspects of the activity. For example, students could focus on when and how they read the articles (e.g., while drinking coffee at a local coffee shop), thus enhancing feelings of self-control, on how much they are learning and expanding their knowledge of the research topics thus elevating their feelings of competence, and on the practical implications sections of the papers (helping them to see the connection to practice) thus increasing their feelings of purpose.

Manz (1986) suggested one additional category of self-leadership strategies: selfleadership of thought patterns. Neck and Manz $(1992,1996)$ subsequently developed these ideas more fully under the label thought self-leadership. Thought self-leadership involves the specific cognitive strategies of positive self-talk, mental imagery, and challenging dysfunctional beliefs and assumptions (Neck and Manz 1992, 1996). More recently, selfleadership has been conceptualized as a three-dimensional construct that includes behaviorfocused strategies (i.e., self-management), natural reward-focused strategies, and cognitive thought-focused strategies (i.e., thought self-leadership) (Houghton and Neck 2002; Neck and Houghton 2006; Neck et al. 2020). 


\section{Self-Concordance}

Self-leadership is appealing and effective, in part, because of the underlying human capacity for intentional and purposeful self-regulation of behavior (cf. Bandura 1991). However, although most people set goals and strive to achieve them through self-regulatory processes, they do not always attain their goals and are not always satisfied or motivated when they do. Some scholars have labeled such breakdowns in the self-regulatory process as "self-regulatory failures" (Baumeister and Heatherton 1996). As Locke and Latham (1990, p. 240) have noted, "although people are natural self-regulators in that goal-directedness is inherent in the life process, they are not innately effective self-regulators." Other researchers have argued that flaws in cognitive processes stem from selecting or adopting goals that do not align well with the individual's values and interests (Sheldon and Elliot 1999). Self-concordance is defined as a state in which one's tasks and activities are closely aligned with one's interests and core values (Sheldon and Elliot 1999). Empirical research studies have shown that people who experience a high level of self-concordance put forth greater effort and have greater vitality, mood, and life satisfaction than people with lower levels of self-concordance (Sheldon and Elliot 1999; Sheldon and Kasser 1995). Additional research examining self-concordance in the context of work has yielded similar results, showing positive relationships for self-concordance with goal attainments and goal striving (Bono and Judge 2003; Judge et al. 2005), in-role and extra-role performance (Greguras and Diefendorff 2010) and leadership emergence (Adriasola et al. 2011). Furthermore, selfconcordance has recently been examined in relation to goal choices. Sheldon et al. (2019) found that goal self-concordance helps people choose goals that are intrinsically motivating and satisfying, lending additional empirical support for the connection between selfconcordance and positive forms of motivation.

Building on the work of Manz (1986), Unsworth and Mason (2016) argued that selfmanagement strategies including self-observation, self-goal-setting, and self-reward are generally ineffective when used in isolation. They hypothesized, and provided support with their empirical findings, that self-management strategies and natural reward processes entailing feelings of competence, self-control, and purpose, combine in an interactive and multiplicative fashion to create synergistic outcomes, rather than in a simple complementary, additive manner in which the presence of one can offset the absence of the other (Unsworth and Mason 2016). Stated differently, these results suggest that self-management and natural reward processes work together and interactively to enhance one's state of self-concordance, leading to increased motivation and striving, and ultimately to valuable individual performance outcomes. If the processes of self-observation, self-goal-setting, and self-reward are unmoored from one's underlying core values, interests, and self-identity, then lower levels of effort and motivation are likely to occur (cf. Manz 1986). However, natural reward processes focused on enhancing feelings of competence, self-control, and purpose, can be used to link self-regulatory and goal-setting processes to one's underlying authentic values and interests (cf. Manz 2015) leading to a self-concordant state (Sheldon and Elliot 1999; Unsworth and Mason 2016).

\section{A Model of Gamification and Self-Leadership}

We will now develop and a present our proposed model of gamification, self-leadership, self-concordance, and valued individual outcomes (see Figure 1) and discuss how these concepts are related. In short, we propose that various gamification elements, when applied in conjunction with one another, will simultaneously activate self-management and natural reward processes that will interact to enhance self-concordance and ultimately individual outcomes. It is important to note that our model does not incorporate self-leadership's constructive-thought focused strategies. Although these cognitive strategies are an important part of the full self-leadership picture, we omit them from our model because we propose that the effects of gamification are mediated primarily through the interaction of self-management and natural rewards, and not through constructive-thought processes. 


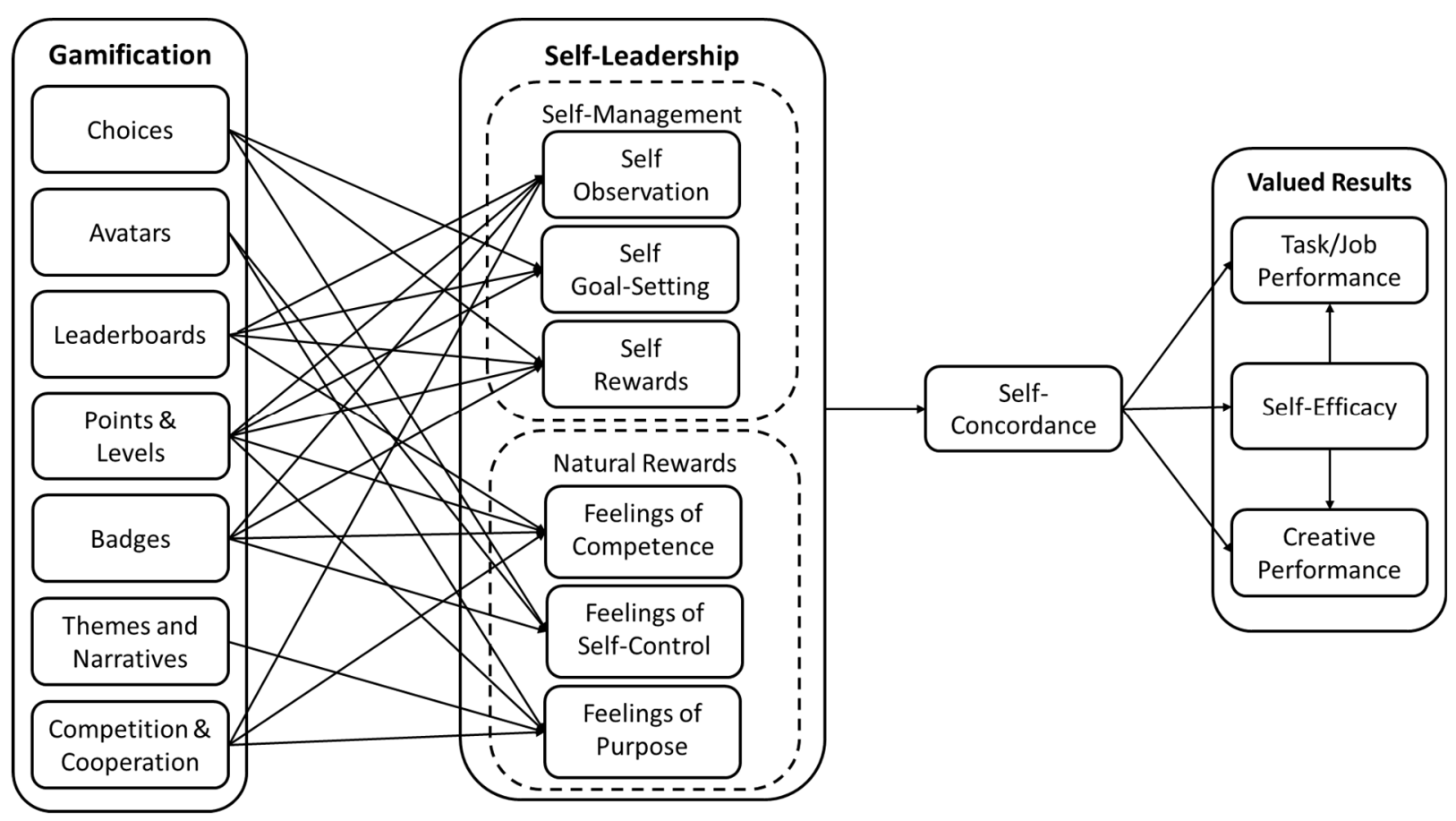

Figure 1. A conceptual framework for understanding the relationships between gamification elements and self-concordance, as mediated by self-leadership and how these can lead to valued individual outcomes.

The first set of links in our model (see Figure 1) focus on how the various commonly used gamification elements affect the self-management and natural reward processes described in self-leadership theory. Each of the gamification elements are proposed to affect multiple aspects of self-leadership, making gamification one possible antecedent to selfleadership and the benefits it can impart. Yet, no single gamification element activates all of the aspects of self-leadership; therefore, bundles of these game elements should be used in concert to see the benefits discussed herein. This bundling concept may help to explain why some previous gamification researchers have found mixed results when studying gamification elements. If elements are studied in isolation, they likely will have less effect on the potential mediating and multiplicative influence of self-leadership. We, therefore, organize this section of proposition development around the individual self-leadership aspects of self-management (self-observation, self-goal setting, and self-rewards) and natural rewards (feelings of competence, feelings of self-control, and feelings of purpose). It is important to note that our propositions for this first set of linkages are based largely on theoretical and logical arguments, as we have seen no evidence of empirical work done to test these relationships directly. Therefore, the links proposed in this model between the gamification elements and self-leadership were derived through discussion and molded based on theory and logic.

The second link important to this model is that between individual aspects of selfleadership and self-concordance. A proposition statement and more full explanation follow below, but the primary point here is that the aspects of self-leadership are positioned within this model as fulfilling a mediating role between gamification and self-concordance. However, we do not suggest full mediation in this model, as a direct effect might exist between some or all of the gamification elements and self-concordance and/or the valued results. For the sake of keeping this model as simple as possible, we focus in the indirect mediating effects and do not show possible direct linkages that may exist.

The third link in our model is between self-concordance and the various individual valued results. This linkage is discussed further in the proposition development section where we rely heavily on past empirical studies to provide support for this proposed linkage. 


\subsection{Elements Influencing Self-Management}

Self-observation is a critical part of the self-management process wherein a person examines their progress and gathers feedback about their performance. Various gamification elements are well-suited to provide this feedback. As discussed earlier, points and levels often serve as a feedback mechanism for performance that can be quantified. Points and levels, therefore, can provide quick and accessible feedback to a person and may be constantly updated based on ongoing performance. Likewise, leaderboards give an employee significant information on how they are performing in relation to others. Badge systems also give a kind of feedback and can serve as a reminder to the employee as to their past performance and what is valued by the organization. Lastly, competition and cooperation can also serve a role in providing data and feedback to an employee. Teammates often give feedback to one another during tactical or strategic decision-making in a cooperative setting. Similarly, if a person is losing or their team is losing in a competitive situation, this too can provide valuable information that is useful in self-observation. Therefore, we suggest the following:

Proposition 1. The self-observation process is triggered by leaderboards, points and levels, badges, and competition and cooperation.

Gamification may also be a useful tool to encourage the self-goal setting process for employees. Gamification furnishes quantifiable indicators of performance, upon which employees can focus and base their goals. The elements available within a gamified system allows employees to set their goals based on outcomes, such as ranking on the leaderboard, for instance. They may set a goal to be in the top five or top ten in the leaderboard rankings, or they might just want to get ranked above a co-worker. Either way, goals can be self-set and with a great amount of autonomy. Furthermore, points and levels are another easy and accessible way through which individuals can set goals for themselves. A person might wish to achieve a certain level as their goal or set a point amount they wish to reach. For these reasons, we propose:

Proposition 2. The self-goal setting process is triggered by choices, leaderboards, and points and levels.

The final aspect of self-management is self-rewards. The choices involved with selfgoal setting also play a part in the self-reward process. Reaching goals that employees set for themselves is likely to be self-rewarding. For example, an employee who has achieved a new rank within a leaderboard system can feel rewarded by having done so, especially if this was important to them or they had set goals based on this achievement. Similarly, gaining points and levels can be rewarding on their own, but getting this positive form of feedback can activate self-rewards based on these systems. Badge systems are probably the best way to encourage self-rewarding processes. Badges are gained when a person performs a task that is both valued and outside their normal scope of duties. Therefore, when a person sees that they have gained a badge, they feel recognized and rewarded for their pro-organizational work. It is important to note that although these game elements could be conceptualized as extrinsic rewards, we see them more as providing gamified feedback that employees internalize as intangible self-rewards (e.g., congratulating oneself for having earned a badge or moving up the leaderboard) or tangible self-rewards (e.g., taking oneself out to lunch at a favorite café for having reached a certain level). Based on these arguments, we propose that:

Proposition 3. The self-rewards process is triggered by choices, leaderboards, points and levels, and badges. 


\subsection{Elements Influencing Natural Rewards}

As much as gamification elements might be useful in encouraging the self-management aspects of self-leadership, they may be even more important in terms of their ability to evoke the feelings associated with natural rewards. In fact, most gamification researchers call on self-determination theory (Deci and Ryan 1980,1983) to explain why these gamification elements have motivational properties (Sailer and Homner 2020; Landers et al. 2015; Cardador et al. 2017). As the natural rewards dimension of self-leadership is founded on self-determination theory, we expect to see strong relationships between gamification elements and feelings of natural rewards.

Feelings of competence come from the successful completion of tasks and from positive feedback about one's performance. Gamification offers numerous avenues to attain this positive feedback. For instance, gaining in the ranking on a leaderboard can result in feelings of competence. This is especially true if a person is doing very well on a particular leaderboard. Similarly, attaining points and levels work as positive feedback and should instill feelings of competence in an employee. As gamification systems generally offer real-time feedback, usually in terms of points, employees can evoke feelings of competence very quickly. Earning badges can also be useful in providing a feeling of competence. Oftentimes, available badges are shown to participants in advance and when they are achieved, they light up or color is added to them in the virtual setting. Therefore, people might seek to get all of their badges to light up, which would almost certainly inspire a feeling of competence in an employee. Lastly, feelings of competence could be encouraged via competition and cooperation. In competitive contexts, if a person is part of a winning team, they will likely feel some level of competence. Similarly, if a person is an integral part of a collaborative team, they will feel that the team successes are, at least in part, due to their own competence. Therefore, we offer the following proposition:

Proposition 4. Feelings of competence are evoked by leaderboards, points and levels, badges, and competition and cooperation.

Feelings of self-control can be difficult to attain in organizational settings due to constraints on employees' time, choices, and levels of autonomy. Gamification could be useful in instilling a feeling of control in such tightly controlled environments. For instance, since a well-designed gamification system will include choices and various paths for people to take to meet objectives and organizational performance goals, this should evoke feelings of self-control for employees operating within such a system. Avatars should also be useful in this regard. Avatar selection and modification should allow individuals to experience more feelings of self-control. After all, they are getting to make these choices as to how they will be represented in the gamified environment. Furthermore, since badges are awarded for completing tasks outside the normal scope of the job, an employee completing these should have feelings of self-control when choosing whether to engage in such activities. Therefore, we suggest the following:

Proposition 5. Feelings of self-control are evoked by choices, avatars, and badges.

Feeling of purpose at work can be a highly individualistic issue that can be difficult for organizations to evoke or enhance. A well-worded and inspiring vision and mission statement might work to do this for some, but others might ignore such an offering from an organization and take a more cynical view. Still, it is possible that certain gamification elements incorporated into the task or job environment might help overcome this issue for organizations. For instance, the use avatars and themes could be potentially impactful for encouraging these feelings of purpose. As discussed above, themes and narratives can add meaningful context to mundane tasks and jobs, making them more interesting. People who can suspend disbelief or allow themselves to be lost in a good narrative might thrive under such conditions at work. Instead of pressuring an employee to complete 
a project on time for a client, the employee could be encouraged to imagine that these tasks are instead preparations to slay a dragon at the top of a mountain. This type of contextual meaning could artificially encourage feelings of purpose in one's work, but artificial or not, many of the feelings of natural rewards remain. Similarly, if employees avatars are representations of themselves, then experiencing success with these avatars could be psychologically linked to their own success. Lastly, cooperation and competition in gamified environments should also lead to feelings of purpose for employees. They might feel the need to win in a competition or be a good team member in a coloration. Either way, these should evoke feelings of purpose in employees. Therefore, we posit:

Proposition 6. Feelings of purpose are evoked by avatars, themes and narratives, and competition and cooperation.

\subsection{The Mediating Effects of Self-Leadership}

Our conceptual model of gamification and self-leadership suggests that the positive effects of the various gamification elements will be translated into a state of selfconcordance via the interactive and multiplicative effects of self-management and natural reward processes within the larger framework of self-leadership. As outlined in detail above, Unsworth and Mason (2016) presented compelling evidence in support of their arguments that self-management processes will be relatively ineffective when used in isolation. They found that self-management and natural reward processes interact in a multiplicative way to affect outcomes, as opposed to a more simplistic additive manner wherein more self-management could offset fewer natural rewards and vice versa (Unsworth and Mason 2016). Most notably, they argued that the feelings of natural rewards (i.e., competence, self-control, and purpose) connect self-managing processes (i.e., self-observation, self-goal-setting, and self-reward) with individuals' true interests and core values, resulting in a self-concordant state (Unsworth and Mason 2016). Our model builds on the work of Unsworth and Mason (2016) by explaining one potentially effective means through which the interactive and multiplicative effects of the two joint facets of self-leadership may be triggered and evoked. We posit that bundles of gamification elements, working together in a gamified system, have the potential to simultaneously activate elements of self-management and natural reward leading to the synergistic and multiplicative effect described by Unsworth and Mason (2016). Here, again, we note that specific gamification elements in isolation are not likely to simultaneously engage the full spectrum of both self-managing and naturally rewarding processes that will lead to the interactive mediating effects described above. Mixed results of previous gamification research exploring individual elements (e.g., Kyewski and Krämer 2018) may be attributable to a lack of understanding of the mediating effect explained by our model. We formalize the explanation offered by our model with the following:

Proposition 7. The self-leadership dimensions of self-management and natural rewards will interact to mediate the effects of gamification elements on self-concordance.

\subsection{Self-Concordance and Valued Outcomes}

Finally, our conceptual model suggests that a state of self-concordance will result in valued individual outcomes. When individuals experience a high degree of self-concordance, they are likely to be more satisfied, more motivated, and more likely to increase their efforts when compared to individuals experiencing a disconnect from their core values and interests (Sheldon and Elliot 1999; Sheldon and Kasser 1995). Indeed, as noted earlier, empirical research has found positive relationships between self-concordance and goal outcomes (Bono and Judge 2003; Judge et al. 2005) and work performance (Greguras and Diefendorff 2010). Based on these findings, it seems reasonable to suggest that a state of self-concordance would be related to key individual performance outcomes such as task performance, self-efficacy, and creativity. Consequently, we advance: 
Proposition 8. A state of self-concordance will lead to valued individual outcomes including job performance, self-efficacy, and creative performance.

\section{Discussion}

This article develops and presents a conceptual model of gamification and selfleadership. More specifically, we propose a series of linkages from gamification, as a job design system, through self-leadership to self-concordance, which is associated with various positive individual and organizational-level outcomes. Importantly, our model shows that game elements, when bundled with other game elements, can activate both the selfmanagement and natural rewards aspects of self-leadership simultaneously. Furthermore, these two aspects of self-leadership are useful in promoting a state of self-concordance within individuals, thereby increasing self-efficacy, creativity, and job/task performance within organizations.

As our model is based on somewhat abstract theoretical mechanisms and proposed relationships, it may be useful to discuss effects shown in our model in the context of a real-world example, in order to establish its practicality. Most people who work in the university environment have likely been required to participate in various training sessions (often virtually) in order to adhere to university or governmental policies. For instance, many academic researchers have participated in human subject research training for their Institutional Review Board (IRB), in addition to training for travel and research expense reports, as well as multiple others (e.g., Title IX, harassment and abuse, active shooter training, etc.). As training is required and, in some cases, not especially intrinsically interesting, motivation to complete the training modules is sometimes lacking. However, what if these training modules made use of gamification strategies and systems to increase user motivation and engagement? If a bundle of these gamification elements (points, themes, avatars, and choices) were built into these training modules, then that should, according to our propositions, increase self-management strategies and natural rewarding states for individuals participating in this training. If these two aspects of self-leadership interactively create a feeling of self-concordance for individuals ("this training is important to me and in alignment with my values"), then it should lead to better training outcomes for these modules (increased self-efficacy and training performance). For instance, if the IRB training was themed so that the trainees were participants in a poorly designed study and could gain points by correcting the researcher, would that make it more engaging and interesting? We suggest that it would, and that trainees would be motivated to gain these points and interact with the theme. Furthermore, participants could be given options for an avatar or character they could portray in the scenario and offer choices about paths they could take within the training, while still keeping with the learning objectives of the module. Although some of these applications could lengthen the training time, it might be enjoyable enough that participants might not notice the extra time spent, and if the outcomes of the training were better, this extra time and development might be warranted.

This research contributes to the gamification literature by offering a closer look at one possible underlying mechanism through which game elements can increase motivation and other valued outcomes. The gamification literature generally suffers from a lack of theoretical development. Indeed, as Landers (2014, p. 753) has explained, "without a theoretical model linking the specific approaches taken by instructional designers to gamify learning with the outcomes of those efforts, it will never be clear why these techniques influence outcomes as they do." We hope that the model presented here provides some conceptual clarity regarding how and why gamification elements influence outcomes. Furthermore, our model might help to explain some of the mixed results found in the gamification literature. If gamification elements are tested empirically and in isolation from one another, no one element is able to tap into each of the aspects of self-leadership, which could explain why they fail. Consequently, our theoretical model might provide some insights for future gamification research. 
Our paper also contributes to the self-leadership literature by positioning selfmanagement and natural rewards as interactive mediators between the two potentially important constructs of gamification and self-concordance. As mentioned earlier, selfleadership is often studied as an antecedent to individual and organizational outcomes. We depart from that norm by positioning self-leadership as a mediating mechanism that can help us better understand the effects of organizational practices. Interestingly, in so doing, we reframe the current discussion of self-leadership beyond self-leadership as simply the application of prescriptive strategies and toward self-leadership as a more nuanced and higher-level self-influence process (cf. Manz 1986, 2015).

Still, there are some limitations within this current research that must be discussed. The most salient limitation comes from the issue of how the linkages between gamification elements and self-leadership were derived. Though we offer some logical and theoretical explanations for why we propose these various relationships, these are currently without any empirical support. Furthermore, other gamification or self-leadership researchers may find linkages where we did not or may argue that some of these relationships are thin or perhaps non-existent. We have focused on linkages we consider to be most supported by our understanding of these constructs. Future researchers may improve upon this model and offer different linkages based on their own understanding.

This research offers a conceptual model of proposed relationships that represents an important first step toward understanding these potentially important constructs and the relationships between them. Therefore, we suggest that this paper provides ample opportunities for future research based on this model. For instance, future researchers might consider testing these relationships empirically, along with the ideas we presented about bundling the various game elements. Furthermore, it would be useful to know if certain bundles of these game elements work better than others and in what situations. Empirical testing could involve a wide variety of contexts, so that practitioners might know which bundles should be used in job or system design. For instance, do badge systems work best in employee development contexts, but not as well in performance evaluations? Future researchers could also examine the usefulness of this model when considering the various boundary conditions that may exist for the proposed relationships. For example, there are likely many dispositional moderators that could affect these relationships or even create inverse relationships to those proposed. If, for instance, an individual is opposed to games and game-like environments, they might actually act out against any system that incorporates them. Instead of creating self-concordance, it might have the opposite effect. Scholars should investigate such issues and may find them to be fruitful avenues of research.

In conclusion, if organizations are using gamification systems and practices more in the workplace setting, then, as researchers, we should try to understand the results and why these game elements work (or do not work). If the outcomes for these systems are generally positive and organizations continue to use them based solely on the results, we run the risk of dustbowl empiricism, or continuing without the guidance and understanding that comes from a theoretically sound practice. It is incumbent on us as researchers to do this work and understand why we see the results we do in the work environment. We hope this article serves as one such step towards that ultimate goal.

Author Contributions: Conceptualization, R.A.O. and J.D.H.; Writing—original draft preparation, R.A.O. and J.D.H.; writing - review and editing, R.A.O. and J.D.H.; visualization, R.A.O. All authors have read and agreed to the published version of the manuscript.

Funding: This research received no external funding.

Institutional Review Board Statement: Not applicable.

Informed Consent Statement: Not applicable.

Data Availability Statement: Not applicable.

Conflicts of Interest: All authors declare that they have no conflict of interest. 


\section{References}

Adriasola, Elisa, Andrea R. Steele, David V. Day, and Kerrie L. Unsworth. 2011. Leader Identity: Using Goal Hierarchy Self-Concordance to Understand Leader Emergence. Paper presented at 26th Annual SIOP Conference, Chicago, IL, USA, April 14-16.

Aldemir, Tugce, Berkan Celik, and Goknur Kaplan. 2018. A Qualitative Investigation of Student Perceptions of Game Elements in a Gamified Course. Computers in Human Behavior 78: 235-54. [CrossRef]

Andrasik, Frank, and Judy S. Heimberg. 1982. Self-Management Procedures. In Handbook of Organizational Behavior Management. Edited by Lee W. Frederikson. New York: Wiley, pp. 219-47.

Armstrong, Michael B., and Richard N. Landers. 2018. Gamification of Employee Training and Development. International Journal of Training and Development 22: 162-69. [CrossRef]

Armstrong, Michael B., Jared Z. Ferrell, Andrew B. Collmus, and Richard N. Landers. 2016. Correcting Misconceptions about Gamification of Assessment: More than SJTs and Badges. Industrial and Organizational Psychology 9: 671-77. [CrossRef]

Bandura, Albert. 1991. Social Cognitive Theory of Self-Regulation. Organizational Behavior and Human Decision Processes 50: $248-87$. [CrossRef]

Barata, Gabriel, Sandra Gama, Joaquim Jorge, and Daniel Gonçalves. 2017. Studying Student Differentiation in Gamified Education: A Long-Term Study. Computers in Human Behavior 71: 550-85. [CrossRef]

Baumeister, Roy F., and Todd F. Heatherton. 1996. Self-Regulation Failure: An Overview. Psychological Inquiry 7: 1-15. [CrossRef]

Baxter, Ryan J., D. Kip Holderness, and David A. Wood. 2016. Applying Basic Gamification Techniques to It Compliance Training: Evidence from the Lab and Field. Journal of Information Systems 30: 119-33. [CrossRef]

Bedwell, Wendy L., Davin Pavlas, Kyle Heyne, Elizabeth H. Lazzara, and Eduardo Salas. 2012. Toward a Taxonomy Linking Game Attributes to Learning. Simulation $\mathcal{E}$ Gaming 43: 729-60. [CrossRef]

Bono, Joyce E., and Timothy A. Judge. 2003. Self-Concordance at Work: Toward Understanding the Motivational Effects of Transformational Leaders. Academy of Management Journal 46: 554-71. [CrossRef]

Buckley, Patrick, Elaine Doyle, and Shane Doyle. 2017. Game on Student' Perceptions of Gamified Learning. Educational Technology and Society 20: 1-10.

Cardador, M. Teresa, Gregory B. Northcraft, and Jordan Whicker. 2017. A Theory of Work Gamification: Something Old, Something New, Something Borrowed, Something Cool? Human Resource Management Review 27: 353-65. [CrossRef]

Charsky, Dennis. 2010. From Edutainment to Serious Games: A Change in the Use of Game Characteristics. Games and Culture 5: 177-98. [CrossRef]

Clark, Larry. 2020. How Do You Engage the Workforce of the Future? Harvard Business Publishing. Available online: https: // www.harvardbusiness.org/how-do-you-engage-the-workforce-of-the-future/ (accessed on 1 March 2021).

Cristofaro, Matteo, and Pier Luigi Giardino. 2020. Core Self-Evaluations, Self-Leadership, and the Self-Serving Bias in Managerial Decision Making: A Laboratory Experiment. Administrative Sciences 10: 64. [CrossRef]

DeCharms, Richard. 1968. Personal Causation: The Internal Affective Determinants of Behavior. New York: Academic Press.

Deci, Edward L., and Richard M. Ryan. 1980. Self-Determination Theory: When Mind Mediates Behavior. The Journal of Mind and Behavior 1: 1.

Deci, Edward L., and Richard M. Ryan. 1983. The Basis of Self-Determination: Intrinsic Motivation and Integrated Internalizations. Academic Psychology Bulletin 5: 21-29.

Deterding, Sebastian, Dan Dixon, Rilla Khaled, and Lennart Nacke. 2011. From Game Design Elements to Gamefulness. In Proceedings of the 15th International Academic MindTrek Conference on Envisioning Future Media Environments—MindTrek'11. New York: ACM Press, p. 9. [CrossRef]

Dicheva, Darina, Christo Dichev, Gennady Agre, and Galia Angelova. 2015. Gamification in Education: A Systematic Mapping Study Gamification in Education: A Systematic Mapping Study. Journal of Educational Technology \& Society 18: 75-88. [CrossRef]

Domínguez, Adrián, Joseba Saenz-De-Navarrete, Luis De-Marcos, Luis Fernández-Sanz, Carmen Pagés, and José Javier MartínezHerráiz. 2013. Gamifying Learning Experiences: Practical Implications and Outcomes. Computers and Education 63: 380-92. [CrossRef]

Feng, Yuanyue, Hua Jonathan Ye, Ying Yu, Congcong Yang, and Tingru Cui. 2018. Gamification Artifacts and Crowdsourcing Participation: Examining the Mediating Role of Intrinsic Motivations. Computers in Human Behavior 81: 124-36. [CrossRef]

Frayne, Colette A., and Gary P. Latham. 1987. Application of Social Learning Theory to Employee Self-Management of Attendance. Journal of Applied Psychology 72: 387-92. [CrossRef]

Frayne, Colette A., and Gary P. Latham. 1988. Self-Management Training for Increasing Job Attendance: A Follow-up and a Replication. Academy of Management Proceedings 1988: 206-10. [CrossRef]

Greguras, Gary J., and James M. Diefendorff. 2010. Why Does Proactive Personality Predict Employee Life Satisfaction and Work Behaviors? A Field Investigation of the Mediating Role of the Self-Concordance Model. Personnel Psychology 63: 539-60. [CrossRef]

Hamari, Juho. 2017. Do Badges Increase User Activity? A Field Experiment on the Effects of Gamification. Computers in Human Behavior 71: 469-78. [CrossRef]

Hanus, Michael D., and Jesse Fox. 2015. Assessing the Effects of Gamification in the Classroom: A Longitudinal Study on Intrinsic Motivation, Social Comparison, Satisfaction, Effort, and Academic Performance. Computers and Education 80: 152-61. [CrossRef]

Houghton, Jeffery D., and Christopher P. Neck. 2002. The Revised Self-Leadership Questionnaire:Testing a Hierarchical Factor Structure for Self-Leadership. Journal of Managerial Psychology 17: 672-91. [CrossRef] 
Judge, Timothy A., Joyce E. Bono, Amir Erez, and Edwin A. Locke. 2005. Core Self-Evaluations and Job and Life Satisfaction: The Role of Self-Concordance and Goal Attainment. Journal of Applied Psychology 90: 257-68. [CrossRef] [PubMed]

Kerr, Steven, and John M. Jermier. 1978. Substitutes for Leadership: Their Meaning and Measurement. Organizational Behavior and Human Performance 22: 375-403. [CrossRef]

Kyewski, Elias, and Nicole C. Krämer. 2018. To Gamify or Not to Gamify? An Experimental Field Study of the Influence of Badges on Motivation, Activity, and Performance in an Online Learning Course. Computers and Education 118: 25-37. [CrossRef]

Landers, Richard N. 2014. Developing a Theory of Gamified Learning: Linking Serious Games and Gamification of Learning. Simulation $\mathcal{E}$ Gaming 45: 752-68. [CrossRef]

Landers, Richard N., and Michael B. Armstrong. 2017. Enhancing Instructional Outcomes with Gamification: An Empirical Test of the Technology-Enhanced Training Effectiveness Model. Computers in Human Behavior 71: 499-507. [CrossRef]

Landers, Richard N., Elena M. Auer, Andrew B. Collmus, and Michael B. Armstrong. 2018. Gamification Science, Its History and Future: Definitions and a Research Agenda. Simulation and Gaming 49: 315-37. [CrossRef]

Landers, Richard N., Kristina N. Bauer, and Rachel C. Callan. 2017. Gamification of Task Performance with Leaderboards: A Goal Setting Experiment. Computers in Human Behavior 71: 508-15. [CrossRef]

Landers, Richard N., Kristina N. Bauer, Rachel C. Callan, and Michael B. Armstrong. 2015. Psychological Theory and the Gamification of Learning. In Gamification in Education and Business. Cham: Springer International Publishing, pp. 165-86. [CrossRef]

Locke, Edwin A., and Gary P. Latham. 1990. A Theory of Goal Setting E Task Performance. Englewood Cliffs: Prentice-Hall.

Manz, Charles C. 1986. Self-Leadership: Toward an Expanded Theory of Self-Influence Processes in Organizations. Academy of Management Review 11: 585-600. [CrossRef]

Manz, Charles C. 1991. Leading Employees to Be Self-Managing and beyond: Toward the Establishment of Self-Leadership in Organizations. Journal of Management Systems 3: 15-24.

Manz, Charles C. 2015. Taking the Self-Leadership High Road: Smooth Surface or Potholes Ahead? Academy of Management Perspectives 29: 132-51. [CrossRef]

Manz, Charles C., and Henry P. Sims. 1980. Self-Management as a Substitute for Leadership: A Social Learning Theory Perspective. Academy of Management Review 5: 361-67. [CrossRef]

Mekler, Elisa D., Florian Brühlmann, Alexandre N. Tuch, and Klaus Opwis. 2017. Towards Understanding the Effects of Individual Gamification Elements on Intrinsic Motivation and Performance. Computers in Human Behavior 71: 525-34. [CrossRef]

Nacke, Lennart E., and Sebastian Deterding. 2017. The Maturing of Gamification Research. Computers in Human Behavior 71: 450-54. [CrossRef]

Neck, Christopher P., and Charles C. Manz. 1992. Thought Self-Leadership: The Influence of Self-Talk and Mental Imagery on Performance. Journal of Organizational Behavior 13: 681-99. [CrossRef]

Neck, Christopher P., and Charles C. Manz. 1996. Thought Self-Leadership: The Impact of Mental Strategies Training on Employee Cognition, Behavior, and Affect. Journal of Organizational Behavior 17: 445-67. [CrossRef]

Neck, Christopher P., and Jeffery D. Houghton. 2006. Two Decades of Self-leadership Theory and Research. Edited by Christopher P. Neck. Journal of Managerial Psychology 21: 270-95. [CrossRef]

Neck, Christopher P., Charles C. Manz, and Jeffery D. Houghton. 2020. Self-Leadership: The Definitive Guide to Personal Excellence, 2nd ed. Thousand Oaks: Sage.

Robson, Karen, Kirk Plangger, Jan Kietzmann, Ian McCarthy, and Leyland Pitt. 2014. Understanding Gamification of Consumer Experiences. Advances in Consumer Research 42: 352-57.

Rollings, Andrew, and Dave Morris. 2000. Game Architecture and Design. Scottsdale: Coriolis.

Sailer, Michael, and Lisa Homner. 2020. The Gamification of Learning: A Meta-Analysis. Educational Psychology Review 32: 77-112. [CrossRef]

Sailer, Michael, Jan Ulrich Hense, Sarah Katharina Mayr, and Heinz Mandl. 2017. How Gamification Motivates: An Experimental Study of the Effects of Specific Game Design Elements on Psychological Need Satisfaction. Computers in Human Behavior 69: 371-80. [CrossRef]

Saks, Alan M., and Blake E. Ashforth. 1996. Proactive Socialization and Behavioral Self-Management. Journal of Vocational Behavior 48: 301-23. [CrossRef]

Santhanam, Radhika, De Liu, and Wei Cheng Milton Shen. 2016. Gamification of Technology-Mediated Training: Not All Competitions Are the Same. Information Systems Research 27: 453-65. [CrossRef]

Sheldon, Kennon M, and Tim Kasser. 1995. Coherence and Congruence: Two Aspects of Personality Integration. Journal of Personality and Social Psychology 68: 531-43. [CrossRef]

Sheldon, Kennon M., and Andrew J. Elliot. 1999. Goal Striving, Need Satisfaction, and Longitudinal Well-Being: The Self-Concordance Model. Journal of Personality and Social Psychology 76: 482-97. [CrossRef]

Sheldon, Kennon M., Mike Prentice, and Evgeny Osin. 2019. Rightly Crossing the Rubicon: Evaluating Goal Self-Concordance Prior to Selection Helps People Choose More Intrinsic Goals. Journal of Research in Personality 79: 119-29. [CrossRef]

Silic, Mario, and Paul Benjamin Lowry. 2020. Using Design-Science Based Gamification to Improve Organizational Security Training and Compliance. Journal of Management Information Systems 37: 129-61. [CrossRef]

Smith, Helen Claire. 2018. Finding Purpose through Altruism: The Potential of 'Doing for Others' during Asylum. Journal of Occupational Science 25: 87-99. [CrossRef] 
Statt, Nick. 2021. Amazon Expands Gamification Program That Encourages Warehouse Employees to Work Harder. The Verge. Available online: https://www.theverge.com/2021/3/15/22331502/amazon-warehouse-gamification-program-expand-fcgames (accessed on 27 February 2021).

Stewart, Greg L., Stephen H. Courtright, and Charles C. Manz. 2011. Self-Leadership: A Multilevel Review. Journal of Management 37: 185-222. [CrossRef]

Stewart, Greg L., Stephen H. Courtright, and Charles C. Manz. 2019. Self-Leadership: A Paradoxical Core of Organizational Behavior. Annual Review of Organizational Psychology and Organizational Behavior 6: 47-67. [CrossRef]

Tansley, Carole, Ella Hafermalz, and Kristine Dery. 2016. Talent Development Gamification in Talent Selection Assessment Centres. European Journal of Training and Development 40: 490-512. [CrossRef]

Unsworth, Kerrie L., and Claire M. Mason. 2016. Self-Concordance Strategies as a Necessary Condition for Self-Management. Journal of Occupational and Organizational Psychology 89: 711-33. [CrossRef]

Vansteenkiste, Maarten, Nathalie Aelterman, and Gert-Jan De Muynck. 2018. Fostering Personal Meaning and Self-Relevance: A Self-Determination Theory Perspective on Internalization. The Journal of Experimental Education 86: 30-49. [CrossRef]

Wee, Siaw Chui, and Weng Wai Choong. 2019. Gamification: Predicting the Effectiveness of Variety Game Design Elements to Intrinsically Motivate Users' Energy Conservation Behaviour. Journal of Environmental Management 233: 97-106. [CrossRef]

White, Robert W. 1959. Motivation Reconsidered: The Concept of Competence. Psychological Review 66: 297. Available online: https:/ / psycnet.apa.org/record/1961-04411-001 (accessed on 27 February 2021).

Wilson, Katherine A., Wendy L. Bedwell, Elizabeth H. Lazzara, Eduardo Salas, C. Shawn Burke, Jamie L. Estock, Kara L. Orvis, and Curtis Conkey. 2009. Relationships Between Game Attributes and Learning Outcomes. Simulation E Gaming 40: $217-66$. [CrossRef] 